12.3;05.6;06.4

\title{
Исследование параметров самосфокусированного электронного пучка, выведенного за анод вакуумного диода
}

\author{
() В.И. Олешко, V.V. Nguyen \\ Национальный исследовательский Томский политехнический университет, Томск, Россия \\ E-mail: oleshko@tpu.ru
}

Поступило в Редакцию 14 октября 2021 г.

В окончательной редакции 29 октября 2021 г.

Принято к публикации 29 октября 2021 г.

\begin{abstract}
Исследованы параметры сильноточного электронного пучка, выведенного из зоны самофокусировки через отверстие в аноде в вакуумную камеру. Параметры пучка определены исходя из измерения зон пространственного распределения разрушений и свечения, возникающих в образцах полиметилметакрилата, установленных на различных расстояниях от анода (автографов электронного пучка). Обнаружено формирование двух электронных пучков: самосфокусированного с высокой плотностью энергии, распространяющегося вдоль оси конуса, обращенного основанием к аноду, с углом при вершине $\sim 7^{\circ}$ и высокоэнергетического пучка низкой плотности, распространяющегося в полом усеченном конусе и окружающего самосфокусированный. Измерены осциллограммы тока и энергия электронных пучков.
\end{abstract}

Ключевые слова: вакуумный диод, электронный пучок, филаментация, самофокусировка, полиметилметакрилат, разрушение, свечение.

DOI: 10.21883/PJTF.2022.04.52075.19053

Исследование процесса кумуляции энергии сильноточных электронных пучков в вакуумных и плазменных диодах представляет интерес для различных научных и прикладных направлений [1-5]. Стимулом проведения таких исследований является общенаучный интерес к двум проблемам: необходимости изучения поведения конденсированных сред при высоких плотностях энергии и получению новых данных о физической природе таких явлений, как филаментация и самофокусировка электронных пучков в диодах со взрывоэмиссионным катодом, механизмы формирования которых окончательно не установлены. Отсутствие последовательной теории явлений филаментации и самофокусировки электронных пучков в вакуумных и газовых диодах сильноточных электронных ускорителей с различными параметрами стимулировало проведение экспериментальных работ, основанных на различных модельных представлениях $[1,4,6-11]$.

В предыдущих работах $[9,12]$ проведены исследования филаментации и самофокусировки сильноточных электронных пучков в вакуумном диоде сильноточного ускорителя электронов с генератором ГИН-600. Было обнаружено формирование множества электронных микропучков высокой плотности, стягивающихся на аноде в центральное пятно самофокусировки. Объемная плотность энергии в пятне самофокусировки в медном аноде достигала $\sim 10^{9} \mathrm{~J} / \mathrm{m}^{3}$, что приводило к испарению материала анода, формированию ударной волны и отколу тыльной поверхности медной мишени.

Для фундаментальных и прикладных исследований процесса взаимодействия мощных электронных пучков с конденсированными средами представляется важным вывести самосфокусированный электронный пучок за анод вакуумного диода и получить максимальную плотность энергии на заданном расстоянии от анода.

Цель настоящей работы - получить информацию о пространственных, временны́х и энергетических параметрах самосфокусированного сильноточного электронного пучка (ССЭП), выведенного за анод вакуумного диода.

Эксперименты были проведены на импульсном ускорителе электронов с генератором ГИН-600, к которому подключался вакуумный диод при давлении $\sim 10^{-2}$ Torr. Максимальная энергия электронов в спектре пучка достигала $T \sim 350 \mathrm{keV}$, длительность импульса тока пучка на полувысоте варьировалась в диапазоне от 2 до $15 \mathrm{~ns}$. Наибольший ток пучка составлял $I_{\max } \approx 2 \mathrm{kA}$. Вакуумный диод был образован трубчатым латунным катодом с радиусом $R=3 \mathrm{~mm}$ и плоским анодом толщиной $\sim 0.5 \mathrm{~mm}$. Аспектное отношение $g=R / d_{C A}$ (где $R-$ радиус катода, $d_{C A}-$ катод-анодный зазор) варьировалось в диапазоне 0.8-1.2.

Электронный пучок выводился из области самофокусировки через отверстие диаметром $\sim 1.5 \mathrm{~mm}$ в медном аноде и распространялся в цилиндрической вакуумной камере диаметром $23 \mathrm{~mm}$ и длиной $15 \mathrm{~mm}$. Пространственная структура пучка регистрировалась по следам разрушений (автографам пучка) образцов из полиметилметакрилата (ПММА), меди и свечению ПММА и сцинтилляторов, устанавливаемых на различных расстояниях $L$ от тыльной поверхности анода. Разрушения, образующиеся в металлах и диэлектриках после однократного импульса облучения, и свечение диэлектриков в момент импульса возбуждения фотографировались зеркальной цифровой фотокамерой SONY DSLR-A500 через микроскоп МБС-10 и микровизором проходящего света 

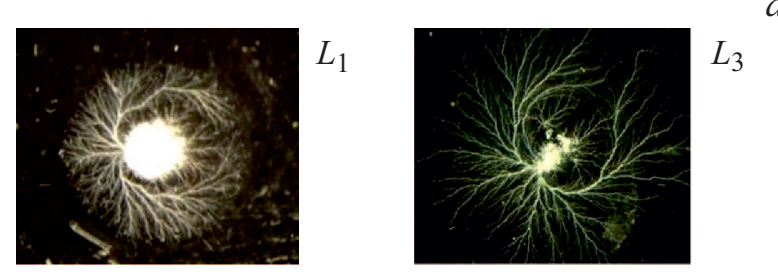

$a$
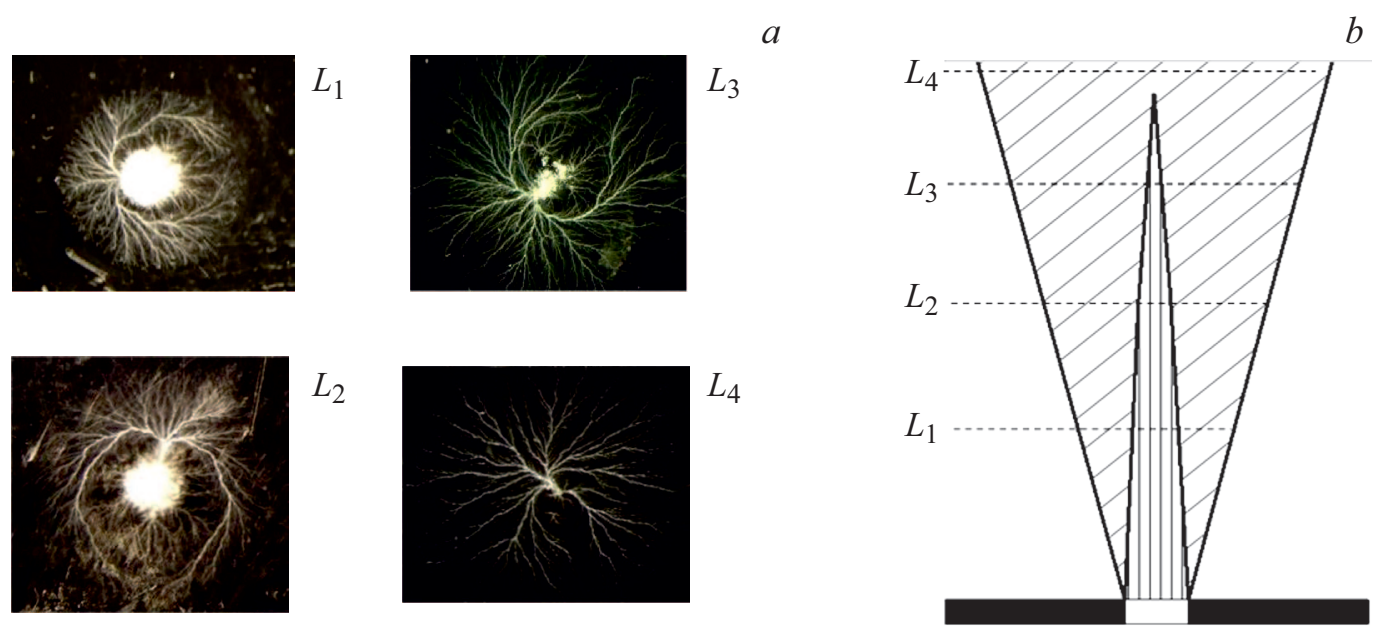

Рис. 1. $a-$ - фотографии разрушений, формируемых в ПММА электронным пучком, выведенным за анод вакуумного диода, на различных расстояниях от анода: $L_{1}=4 \mathrm{~mm}, L_{2}=6 \mathrm{~mm}, L_{3}=9 \mathrm{~mm}, L_{4}=13 \mathrm{~mm} ; b$ - пространственная структура электронных пучков, выведенных за анод вакуумного диода. $d_{C A}=3.5 \mathrm{~mm}, \varnothing_{A}=1.5 \mathrm{~mm}, \emptyset_{C}=6 \mathrm{~mm}$.

$\mu$ Vizo-101. Ток пучка электронов измерялся с помощью коллектора, состоящего из металлического конуса, образующего с корпусом линию с волновым сопротивлением $50 \Omega$. Коллектор устанавливался за алюминиевой фольгой, отделяющей вакуумный диод от атмосферного воздуха. Для регистрации сигналов с коллектора использовался цифровой осциллограф DPO 3034 (300 MHz). Запуск осциллографа производился с помощью синхроимпульса ускорителя. Временно́е разрешение системы регистрации составляло $\sim 2$ ns. Выбор ПММА в качестве материала для диагностики электронного пучка по его свечению и остаточным микроразрушениям определялся тем, что этот диэлектрик имеет низкую плотность, высокую прозрачность и известную морфологию разрушений в виде фигур Лихтенберга (электрического дерева разряда), образующихся при облучении электронными пучками различной плотности, длительности и энергий [13]. Энергия электронов в пучке измерялась двумя методами: по глубине залегания микроразрушений, формируемых электронным пучком в ПММА, и по поглощению электронов в тонких алюминиевых фольгах. Переход в режим испарения регистрировался по следам эрозии, образующимся на поверхности облучаемых мишеней, и по спектрам свечения эрозионной плазмы.

На рис. 1, $а$ приведены автографы, сформированные электронным пучком в ПММА, полученные на различных расстояниях $L$ от анода при $d_{C A}=3.5 \mathrm{~mm}$ и диаметре отверстия в аноде $\emptyset_{A}=1.5 \mathrm{~mm}$. Видно, что неоднородное по диаметру распределение плотности тока пучка приводит к формированию двух типов разрушений. В центральной области облучаемых мишеней образуется совокупность микропузырей диаметром от 10 до $50 \mu \mathrm{m}$, которые возникали, по-видимому, изза взрывного вскипания полимера при его нагреве ССЭП. Пространственная структура, размеры и форма микропузырей, образующихся в ПММА при облучении сильноточным электронным пучком в режиме филаментации и самофокусировки при использовании в качестве анода тонкой $(\sim 10 \mu \mathrm{m})$ алюминиевой фольги, были исследованы ранее в [12].

Вокруг зоны вскипания наблюдаются объемные электрические разряды, которые регистрировались за однократный импульс возбуждения в виде кольцевой структуры как по разрушению (рис. 1,a), так по свечению. По мере увеличения $L$ диаметр центральной зоны разрушения уменьшается и при $L=13 \mathrm{~mm}$ наблюдается только один тип разрушений - каналы электрического пробоя (рис. 1,a). Обращает на себя внимание тот факт, что после рассеяния ССЭП разрядная кольцевая структура не наблюдается, а вместо нее формируется однородная фигура Лихтенберга, что можно объяснить кулоновским отталкиванием заряженных частиц периферийного электронного пучка и их движением в радиальном направлении. Сравнение фотографий разрушения и свечения ПММА показывает идентичность фигур электрического разряда, зарегистрированных по свечению и разрушению. Отличие фотографий заключается только в том, что объемные разрушения в виде микропузырей по свечению не регистрируются. Это можно объяснить как более низкой температурой ПММА в центральной зоне воздействия ССЭП по сравнению с температурой плазмы в каналах электрического пробоя, так и запаздыванием вскипания полимера по отношению к процессу развития электрических разрядов. Глубина залегания микропузырей от облучаемой поверхности составляет 20-70 $\mu \mathrm{m}$, а каналов электрического пробоя - 350-450 $\mu \mathrm{m}$, что соответствует средней энергии электронов в ССЭП и периферийном электронном пучке $\sim 70$ и $\sim 220 \mathrm{keV}$ соответственно.

Уменьшение величины катод-анодного зазора до $d_{C A}=2.5 \mathrm{~mm}$ приводит к увеличению плотности 

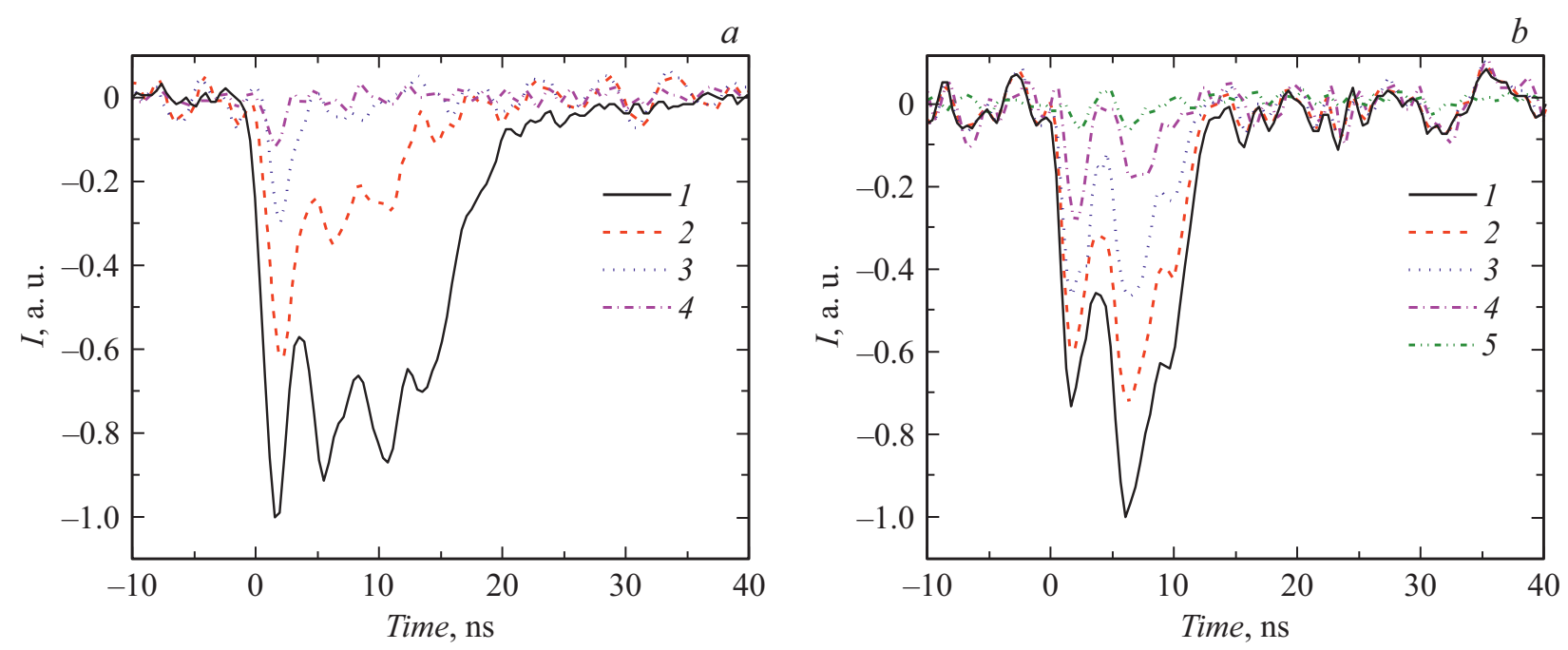

Рис. 2. Осциллограммы тока электронного пучка, выведенного за анод вакуумного диода, после прохождения поглощающих алюминиевых фольг толщиной $30(1), 80(2), 130(3), 230(4)$ и $280 \mu \mathrm{m}(5) . a-$ ток ССЭП, $b-$ ток ВСЭП. $d_{C A}=3.5 \mathrm{~mm}$, $\emptyset_{A}=1.5 \mathrm{~mm}, \varnothing_{C}=6 \mathrm{~mm}$.

энергии центрального ССЭП, что подтверждается образованием эрозионных пятен на металлических мишенях и глубоких кратеров в ПММА с выбросом продуктов абляции и формированием на облучаемой поверхности полимерных нитей.

При этом периферийный высокоэнергетический сильноточный электронный пучок (ВСЭП), регистрируемый в ПММА по каналам электрического пробоя и по свечению сцинтилляторов, никак не проявляет себя на металлических мишенях, что связано с низкой плотностью энергии ВСЭП. Пространственная структура двух электронных пучков, восстановленная по результатам изучения морфологии разрушений в ПММА, представлена на рис. $1, b$.

Информация о временны́х и энергетических параметрах ССЭП и ВСЭП была получена из измерений осциллограмм тока. Для разделения электронных пучков на расстоянии $L$ устанавливались диафрагмы с отверстиями, которые выделяли центральный самосфокусированный или периферийный электронные пучки. На осциллограммах тока ССЭП (рис. 2, $a$ ) и ВСЭП (рис. 2, $b$ ), прошедших поглощающие алюминиевые фольги различной толщины, хорошо видно несколько максимумов, которые образуются из-за рассогласования диода с формирующей линией. Сравнение двух осциллограмм (рис. 2, $a$ и $b$ ) показывает, что длительность импульса тока ССЭП превышает длительность тока ВСЭП. Энергии электронов ССЭП и ВСЭП также различаются. Видно, что четвертый пик тока ССЭП (рис. 2,a) практически полностью поглощается алюминиевой фольгой толщиной $\sim 80 \mu \mathrm{m}$, а амплитуды второго и третьего импульсов тока уменьшаются более чем в 2 раза. Это означает, что в CСЭП основная доля электронов имеет энергию $\sim 100 \mathrm{keV}$. Что касается ВСЭП, то, как видно из осциллограмм, приведенных на рис. 2, $b$, все три импульса тока присутствуют при суммарной толщине поглощающих алюминиевых фольг $\sim 280 \mu \mathrm{m}$, что соответствует максимальной энергии электронов $\sim 290 \mathrm{keV}$.

Таким образом, в пространстве за анодом регистрируются два электронных пучка с различными параметрами. Первый из них - ССЭП с плотностью энергии, достаточной для испарения металлических и диэлектрических мишеней, и средней энергией электронов в спектре $\sim 100 \mathrm{keV}$ - распространяется в конусе, обращенном основанием к аноду (рис. $1, b$ ), с углом при вершине $\sim 7^{\circ}$. Второй - ВСЭП с плотностью энергии, превышающей пороговую для инициирования электрического пробоя в ПММА $\left(\geqslant 0.2 \mathrm{~J} / \mathrm{cm}^{2}\right)$, и максимальной энергией электронов в спектре $\sim 290 \mathrm{keV}$ - распространяется центрально-симметрично относительно ССЭП в полом усеченном конусе с углом при вершине, обращенной к аноду, $\sim 22^{\circ}$ (рис. $\left.1, b\right)$. Длина транспортировки ССЭП в вакуумной камере длиной $15 \mathrm{~mm}$ и диаметром $23 \mathrm{~mm}$ при $d_{C A}=2.5 \mathrm{~mm}$ и диаметре отверстия в аноде $\emptyset_{A}=1.5 \mathrm{~mm}$ составляет $L \sim 10 \mathrm{~mm}$. Приведенная на рис. $1, b$ пространственная структура ССЭП и ВСЭП, по-видимому, формируется в результате взаимодействия электромагнитных полей двух пучков между собой и со стенками вакуумной камеры. Одна из причин распада ССЭП может быть связана с развитием различного рода неустойчивостей.

\section{Финансирование работы}

Работа выполнена в рамках программы развития ТПУ.

\section{Конфликт интересов}

Авторы заявляют, что у них нет конфликта интересов. 


\section{Список литературы}

[1] D.D. Hinshelwood, R.J. Allen, R.J. Commisso, G. Cooperstein, B.M. Huhman, D. Mosher, D.P. Murphy, P.F. Ottinger, J.W. Schumer, S.B. Swanekamp, S.J. Stephanakis, B.V. Weber, F.C. Young, I. Crotch, J. O'Malley, J.R. Threadgold, IEEE Trans. Plasma Sci., 35 (3), 565 (2007). DOI: $10.1109 /$ TPS.2007.895227

[2] В.Е. Фортов, Физика высоких плотностей энергии (Физматлит, М., 2013).

[3] Б.А. Демидов, В.П. Ефремов, В.А. Петров, А.Н. Мещеряков, Поверхность. Рентгеновские, синхротронные и нейтронные исследования, № 9, 18 (2009). [B.A. Demidov, V.P. Efremov, V.A. Petrov, A.N. Mescheryakov, J. Synch. Investig., 3 (5), 673 (2009).

DOI: $10.1134 / \mathrm{S} 1027451009050036$

[4] Э.Э. Тарумов, Генерация и фокусировка сильноточных релятивистских электронных пучков (Энергоатомиздат, М., 1990).

[5] В.И. Олешко, Пороговые процессы в твердых телах при взаимодействии с сильноточными электронными пучками, автореф. докт. дис. (ТПУ, Томск, 2009).

[6] S. Anishchenko, V. Baryshevsky, N. Belous, A. Gurinovich, E. Gurinovich, E. Gurnevich, P. Molchano, IEEE Trans. Plasma Sci., 45 (10), 2739 (2017). DOI: $10.1109 /$ TPS.2017.2707591

[7] V.I. Baryshnikov, V.L. Paperny, Phys. Plasmas., 25 (8), 083106 (2018). DOI: 10.1088/1361-6463/aa85c4

[8] М.И. Ломаев, В.Ф. Тарасенко, А.В. Дятлов, Изв. вузов. Физика, 62 (6), 68 (2019). DOI: 10.17223/00213411/62/6/68 [M.I. Lomaev, V.F. Tarasenko, A.V. Dyatlov, Russ. Phys. J., 62 (6), 996 (2019). DOI: 10.17223/00213411/62/6/68].

[9] В.И. Олешко, В.Ф. Тарасенко, А.Г. Бураченко, V.V. Nguyen, Письма в ЖТФ, 45 (7), 3 (2019). DOI: 10.21883 /PJTF.2019.07.47526.17640 [V.I. Oleshko, V.F. Tarasenko, A.G. Burachenko, V.V. Nguyen, Tech. Phys. Lett., 45 (4), 309 (2019). DOI: $10.1134 / \mathrm{S} 1063785019040023]$.

[10] Г.А. Месяц, В.Г. Шпак, Письма в ЖТФ, 3 (14), 708 (1977).

[11] А.А. Жерлицын, Б.М. Ковальчук, Н.Н. Педин, ЖТФ, 84 (4), 132 (2014). [A.A. Zherlitsyn, B.M. Koval'chuk, N.N. Pedin, Tech. Phys., 59 (4), 600 (2014). DOI: $10.1134 / \mathrm{S} 1063784214040276]$.

[12] V. Oleshko, A. Yakovlev, V. Tarasenko, V. Nguyen, in Proc. 2020 7th Int. Congress on energy fluxes and radiation effects (EFRE) (IEEE, 2020), p. 906. DOI: $10.1109 /$ EFRE47760.2020.9242003

[13] А.И. Акишин, Космическое материаловедение (НИИЯФ МГУ, М., 2007). 